\title{
The Dominant Lifestyle Type of University Students in Taiwan
}

\author{
Hui-Wen Vivian Tang1*, Mu-Shang Yin², Kuopao Chang3 \\ ${ }^{1}$ Teacher Education Center, Ming Chuan University, Taoyuan City, Chinese Taipei \\ ${ }^{2}$ Department of Travel Management, Hsing Wu University, New Taipei City, Chinese Taipei \\ ${ }^{3}$ Graduate School of Education, Ming Chuan University, Taoyuan City, Chinese Taipei \\ Email: "kshvt00@hotmail.com, yin max@hotmail.com, kuopao@mail.mcu.edu.tw
}

Received 29 May 2015; accepted 7 July 2015; published 14 July 2015

\begin{abstract}
Emotional and psychological health is being recognized as one of the key determinants of an individual's overall wellness. The objective of the study was to detect a sample of university students' dominant lifestyle type with a focus on emotional aspect of health function. A sample of 280 university students in Taiwan was assessed by the Lifestyle Type Indicator (LSTI). The results indicated that the dominant lifestyle type for the sample of university students was Believer (Type B). A gender breakdown analysis showed that there existed a significant difference between male and female students' dominant lifestyle type. Achiever (Type A) was the dominant lifestyle type among male students, while Believer (Type B) was the dominant type of female students. Through the extension of the assessment and intervention processes, the study will provide new opportunities for helping college/university students navigate and pursue meaningful life throughout the challenges and transitional phase of their university life.
\end{abstract}

\section{Keywords}

Lifestyle Type, Emotional Intelligence, Physical and Mental Balance, Personal Wellness

\section{Introduction}

There is a longstanding history of people showing concerns over health, happiness and well-being. A substantial number of studies reveal that unhealthy lifestyle behaviors, such as tobacco/alcohol use, physical inactivity and unhealthy diet can result in insufficient sleep patterns, a decrease in mental well-being, premature morbidity and mortality and other health-related problems [1] [2]. Elaborating on the typology of physical, mental, and social well-being denoted to define "health" provided by the World Health Organization (WHO) in 1964, the Lifestyle Type Indicator (LSTI) initiated by Darwin B. Nelson in 2012 is a forced-choice ranking self-assessment instrument developed on the basis of nearly thirty years of research regarding the impact of emotional capacities on health functions [3]. Focusing explicitly on psychological factors and mental processing that facilitate or impede emotional health, the purpose of the study was to investigate the dominant lifestyle type of university students in

${ }^{*}$ Corresponding author. 
Taiwan as a benchmark to inform emotional areas of health-related lifestyle that needed to be strengthened, as well as facilitated the design of health promotion initiatives for improving emotional functioning of university students.

Specific research questions posted based on the purpose of the study are:

1) What is the dominant lifestyle type of university students in Taiwan measured by LSTI?

2) Is there a significant difference between male and female students' dominant lifestyle types measured by LSTI?

Results of the study would contribute to future lifestyle studies and lifestyle-related educational interventions for students in Taiwan in particular, and other Chinese societies in general.

\section{Literature Review}

\subsection{Conceptualizing Wellness and Healthy Lifestyle}

The World Health Organization (WHO) has reported that close to $60 \%$ of an individual's health-related quality of life is determined by his/her lifestyle [4]. In Taiwan, nearly $60 \%$ of students at all levels surveyed lack interests in physical activity which would jeopardize individuals' health status and quality of life [5]. To promote life quality and health lifestyle of its citizenships, Taiwan, starting from 2007, has initiated a five-year Happy Program inaugurated by the Ministry of Education in an effort to encourage students at all levels to develop physical activity habits and enhance their healthy diet concepts for the purpose of achieving physical and mental balance [6]. The proliferation of research on the underlying causes of unhealthy lifestyle led us to the conceptual changes that conventional approach to health issues, with a concentration on diet and physical education, is woefully inadequate [7]. It was proposed that the identification of mental and physical health hazards which might impede health lifestyle and personal wellness could be broken down into the following five components: physical health, psychological/emotional health, social health, intellectual health, and spiritual health [8] [9]. The five components have to be given equally systematic, if not holistic, importance if Taiwan government were to pursue a comprehensive and effective health education initiative in this regard.

In the pursuit of the educational objectives of holistic healthy lifestyle in systematic ways, many of the theoretical and research concepts of other models were synthesized into the development and refinement of a holistic wellness model that consisted of five dimensions of 1) spirituality (meaning and appreciation for life); 2) selfregulation (combined variable measuring ability to cope with one's self); 3 ) work, leisure, and recreation (ability to integrate these activities into daily life); 4) friendship; 5) love (for self and through social interdependence) [10]. There are additional well-developed holistic wellness models used in research to evaluate an individual's overall well-being, health status, positive mental health, happiness, lifestyle and life quality at an individual level. Among those frequently cited include Wellness Process for Healthy Living (WPHL), WHOQOL-100, the Canadian Index of Well-being (CIW), the Short Form-36 item (SF-36) Health Survey, the Health-Related Quality of Life measure (HRQOL) [11], The Perceived Wellness Survey [12], Optimal Living Profile [13], to mention a few. The aforementioned measurements appear to show that development of instruments measuring wellness, health or lifestyle has been increasing in popularity worldwide.

\subsection{An Emotional Intelligence Framework of Lifestyle}

The relevance of emotional intelligence (EI) to holistic personal well-being and health has received growing attention in recently years. After thirty years of scholarly inquiry into the interrelationship between cognition and emotion for enhancing personal well-being and emotional health, the EI centric model of lifestyle derived from Nelson and Low's emotional learning system serves as the a priori construct based on which a new 60-item forced choice instrument of emotional intelligence, the Lifestyle Type Indicator (LSTI), was developed [3]. The Lifestyle Type Indicator (LSTI) and an education model of emotional intelligence from which it grew provide a synthesis of many schools of thought and practice within psychology which are all concerned with the mind, emotion, and behavior [3] [14].

To provide a comprehensive EI-centric model of human lifestyle behaviors, the basic emotional drives of temperament are displayed by four lifestyle types that are distinguished by an individual's orientation toward task versus people, as well as levels of needs for challenging the status quo versus obtaining security and safety. Lifestyle types measured by LSTI are organized into four general clusters: Believers (Type B), Creators (Type 
C), Achievers (Type A), and Supporters (Type S). Definitions of the four lifestyle types and their corresponding thoughts, behaviors and weaknesses are presented in Figure 1.

\section{Methodology}

\subsection{Sampling and Instrumentation}

A convenience sampling strategy was used to recruit 400 university students from three universities in northern Taiwan. Students above the age of 20 filled out the LSTI in their classes and data collection was completed within the period of December 2014 to March 2015. A total of 326 returned their surveys, yielding a 81.5\% response rate. Forty six data received from the participants were invalid; therefore, the total valid response rate was $70 \%$. The final sample of 280 was comprised of 124 male students and 156 female students.

The instrument used in the research is the Lifestyle Type Indicator (LSTI) constructed and validated by Nelson. The Chinese version of the LSTI was developed based on a general process for the translation and cultural adaption of instruments recommended by the IQOLA group consists of five stages: the translation, the synthesis, the back-translation, the expert committee review and the pre-testing [15]. The whole process of translation took over 3 months and was supervised by the researchers. The LSTI is a 15 blocks forced-choice measure (60 items in total) that takes approximately 30 minutes to complete. In each LSTI forced-choice block, a respondent is asked to assign ranking positions, numbered from 1 (least descriptive of me) to 4 (most descriptive of me), to 4 items $\{\mathrm{B}, \mathrm{C}, \mathrm{A}, \mathrm{S}\}$ according to the extent the items perceived as reflective of the respondent's lifestyle [3]. Composite scores in the questionnaire were derived by adding together the totals of Type B, Type C, Type A and Type S across all blocks. Each individual's 4 lifestyle types were ranked in order of their composite scores of the four types across the 15 blocks. The type scored the highest represented an individual's dominant lifestyle type.

\subsection{Procedure and Design}

To address the first research question, a contingency table analysis was conducted to detect the dominant lifestyle type of the overall sample representing university students in Northern Taiwan. To answer the second research question, the male and females students were divided into two sample groups. A two-way contingency table analysis was computed to investigate male and female students' dominant lifestyles, respectively, and determine if there exists a significant difference between male and female students' dominant lifestyle types.

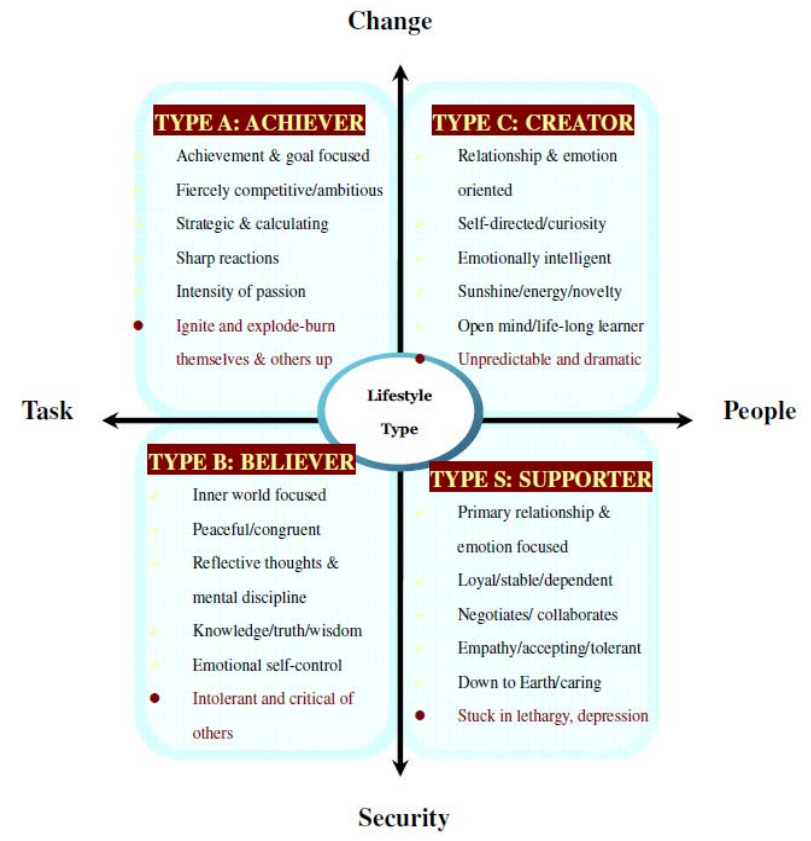

Figure 1. The LSTI continuum. 


\section{Data Analysis Result}

A two-way contingency table analysis was conducted to assess the relationship between lifestyle types and gender of participants in the study. The two variables were lifestyle types with four levels (Type B, Type C, Type A and Type S) and gender with two levels (males and females). The two variables, lifestyle types of and gender, were found to be significantly related, Pearson chi $^{2}(3, N=280)=8.313, p=0.040$, Cramer's V $=0.172$, indicating small strength of relationship. The proportion of total students whose dominant lifestyle was Believer (Type B) with 36\%. Achiever (Type A) with 25.7\% was the second dominant lifestyle type among the sample of students in the study. The proportion of male students with dominant lifestyle type of Achiever (Type A) was $33.1 \%$. The proportion of male students with dominant lifestyle type of Believer (Type B) was 29.0\%.

Significant difference was found on dominant lifestyle types between male and female students in the study. With regard to female students' dominant lifestyle type, $42.3 \%$ of the female students was Believer (Type B). It seems that females were associated with spirituality, peace and virtue, characterizing Believers (Type B) with calm and reflective thinking/behaviors and seem to be at peace with themselves and others. On the other hand, males tended to be more energetic, demonstrating Type A characteristics of competition, high intensity of passion and achievement/goal orientation. Creator (Type C) with less than 19\% in total and Supporter (Type S) with less than $20 \%$ in total were the two least dominant lifestyle types for the sample of participants. Cross-tabulation of lifestyle type breakdowns by gender was presented in Table 1. Chi-square result for lifestyle types by gender was tabulated in Table 2 .

\section{Conclusions, Limitation and Implications}

Emotional health as one of the key determinants of individuals' overall well-being has generated widespread interest in recent years and has become an important indicator of a person's healthy lifestyle. The study was one of the first attempts to investigate university students' dominant lifestyle types with a focus on emotional aspect of health function. The results indicated that the dominant lifestyle type assessed by LSTI was Believer (Type B). A gender breakdown analysis showed that Achiever (Type A) was the dominant lifestyle type among male students, while Believer (Type B) was the dominant type for female students.

The results of the study have contributions to existing literature by specifying that emotional health and well-

Table 1. Cross-tabulation of lifestyle type breakdowns by gender.

\begin{tabular}{|c|c|c|c|c|c|c|}
\hline \multirow{2}{*}{ Gender } & \multicolumn{6}{|c|}{ Lifestyle Types } \\
\hline & Counts \& \% & Believer (B) & Creator $(\mathrm{C})$ & Achiever (A) & Supporter (S) & Total \\
\hline \multirow{2}{*}{ Total } & Numbers within types/total & 102 & 51 & 72 & 55 & 280 \\
\hline & $\%$ of Total & $36.4 \%$ & $18.2 \%$ & $25.7 \%$ & $19.6 \%$ & $100.0 \%$ \\
\hline \multirow{4}{*}{ Males } & Numbers within types/males & 36 & 24 & 41 & 23 & 124 \\
\hline & $\%$ within males & $29.0 \%$ & $19.4 \%$ & $33.1 \%$ & $18.5 \%$ & $100.0 \%$ \\
\hline & $\%$ within type & $35.3 \%$ & $47.1 \%$ & $56.9 \%$ & $41.8 \%$ & $44.3 \%$ \\
\hline & $\%$ of Total & $12.9 \%$ & $8.6 \%$ & $14.6 \%$ & $8.2 \%$ & $44.3 \%$ \\
\hline \multirow{4}{*}{ Females } & Numbers within types/females & 66 & 27 & 31 & 32 & 156 \\
\hline & $\%$ within females & $42.3 \%$ & $17.3 \%$ & $19.9 \%$ & $20.5 \%$ & $100.0 \%$ \\
\hline & $\%$ within type & $64.7 \%$ & $52.9 \%$ & $43.1 \%$ & $58.2 \%$ & $55.7 \%$ \\
\hline & $\%$ of Total & $23.6 \%$ & $9.6 \%$ & $11.1 \%$ & $11.4 \%$ & $55.7 \%$ \\
\hline
\end{tabular}

Table 2. Chi-square result and symmetric measures for lifestyle types by gender.

\begin{tabular}{cccc}
\hline & Pearson $\chi^{2}$ & $p$ Value (Two-Sided) & Cramer's $V$ \\
\hline Gender & 8.313 & 0.040 & 0.172 \\
\hline
\end{tabular}


ness will function as a subsystem and an essential part within the holistic lifestyle framework. Accordingly, each lifestyle type is with its strength and weakness. Imbalanced Type B individuals can be intolerant and critical of others. Imbalanced Type A individuals can ignite and explode-burn themselves up and give third degree burns to those closest to them. It is therefore important to design appropriate training program for particular types of imbalanced individuals in order to improve their holistic personal well being [3]. Integrating LSTI results at some level with results measured by diet and physical aspects of instruments into the holistic construct of health lifestyle would inform universities to evaluate and intervene in the emotional, physical and psychological wellness of individual students [3] [7].

The study is certainly with several limitations. First, self-reported assessments will induce systematic biases. It is recommended that both self- and peer-rating techniques be utilized in future studies to avoid certain biases. Second, results of the sample of students from three universities in northern Taiwan are with limited gernalizability to all university students in Taiwan. Sampling extending to different regions in Taiwan will provide an avenue for further investigation. Lastly, follow-on experimental studies are encouraged to examine to what extent interventions developed based on LSTI assessment improve students' reflections on their current thoughts and behaviors as a criterion for motivating themselves by setting their personal goals, managing their emotion and enhancing their self-management skills. Through the extension of the assessment and intervention processes, the study will provide new opportunities for helping college/university students in Taiwan navigate and pursue meaningful life throughout the challenges and transitional phase of their university life.

\section{Acknowledgements}

This research was funded by a research grant from the Ministry of Science and Technology in Taiwan (MOST-103-2410-H-130-029-).

\section{References}

[1] Lalonde, M. (2002) New Perspective on the Health of Canadians: 28 Years Later. Revista panamericana de salud pública, 12, 149-152. http://dx.doi.org/10.1590/S1020-49892002000900001

[2] Gieck, D.J. and Olsen, S. (2007) Holistic Wellness as a Means to Developing a Lifestyle Approach to Health Behavior among College Students. Journal of American College Health, 56, 29-36. http://dx.doi.org/10.3200/JACH.56.1.29-36

[3] Nelson, D.B. (2012) Lifestyle Type Indicators: Cooperate Training Version [Assessment]. Emotional Intelligence Training and Research Institute (EITRI), Emotional Intelligence Learning Systems, Inc., Corpus Christi, TX.

[4] Ziglio, E., Currie, C. and Rasmussen, V.B. (2004) The WHO Cross-National Study of Health Behavior in School-Aged Children from 35 Countries: Findings from 2001-2002. Journal of School Health, 74, 204-206. http://dx.doi.org/10.1111/j.1746-1561.2004.tb07933.x

[5] Wen, C.P., Wai, J.P.M., Tsai, M.K., Yang, Y.C., Cheng, T.Y.D., Lee, M.C. and Wu, X. (2011) Minimum Amount of Physical Activity for Reduced Mortality and Extended Life Expectancy: A Prospective Cohort Study. The Lancet, 378, 1244-1253. http://dx.doi.org/10.1016/S0140-6736(11)60749-6

[6] Ministry of Education, Taiwan (2007) Physical and Hygiene Education: The Happy Program. http://english.moe.gov.tw/ct.asp?xItem=10706\&ctNode=507\&mp=1

[7] Austin, E.J., Saklofske, D.H. and Egan, V. (2005) Personality, Well-Being and Health Correlates of Trait Emotional Intelligence. Personality and Individual Differences, 38, 547-558. http://dx.doi.org/10.1016/j.paid.2004.05.009

[8] O’Donnell, M.P. (1986) Definition of Health Promotion. American Journal of Health Promotion, 1, 4-5. http://dx.doi.org/10.4278/0890-1171-1.1.4

[9] Felce, D. (1997) Defining and Applying the Concept of Quality of Life. Journal of Intellectual Disability Research, 41, 126-135. http://dx.doi.org/10.1111/j.1365-2788.1997.tb00689.x

[10] Witmer, J.M., Sweeney, T.J. and Myers, J.E. (1998) The Wheel of Wellness. Authors, Greensboro.

[11] Miller, G.D. and Foster, L.T. (2010) Critical Synthesis of Wellness Literature. Faculty of Human and Social Development \& Department of Geography, University of Victoria, Victoria. http://geog.uvic.ca/wellness/Critical Synthesis\%20of $\% 20$ Wellness $\% 20$ Update.pdf

[12] Adams, T., Bezner, J. and Steinhardt, M. (1997) The Conceptualization and Measurement of Perceived Wellness: Integrating Balance across and within Dimensions. American Journal of Health Promotion, 11, 208-218. http://dx.doi.org/10.4278/0890-1171-11.3.208

[13] Renger, R.F., Midyett, S.J., Mas, S., Francisco, G., Erin, T.D., McDermott, H.M. and Hewitt, M.J. (2000) Optimal 
Living Profile: An inventory to Assess Health and Wellness. American Journal of Health Behavior, 24, 403-412. http://dx.doi.org/10.5993/AJHB.24.6.1

[14] Nelson, D.B. and Low, G.R. (2003) Emotional Intelligence: Achieving Academic and Career Excellence. Prentice Hall, Upper Saddle River.

[15] Gandek, B. and Ware, J.E. (1998) Methods for Validating and Norming Translations of Health Status Questionnaires: The IQOLA Project Approach. Journal of Clinical Epidemiology, 51, 953-959. http://dx.doi.org/10.1016/S0895-4356(98)00086-9 